\title{
Augmenting a Child's Reality: Using Educational Tablet Technology
}

\author{
Patricia Tanner, Carly Karas, and Damian Schofield \\ State University of New York, Oswego, NY, USA
}

\author{
Ptanner@oswego.edu, Karas@oswego.edu, schofield@oswego.edu
}

\begin{abstract}
This study investigates the classroom integration of an innovative technology, augmented reality. Although the process of adding new technologies into a classroom setting can be daunting, the concept of augmented reality has demonstrated the ability to educate students and to assist with their comprehension of a procedural task. One half of the students of a sixth grade class were exposed to augmented reality technology when they were assigned the procedural task of building $\mathrm{Lego}^{\mathrm{TM}}$ robots. As a control group, the other half of the class learned how to construct their robots using only the static paper manual that was provided by the manufacturer of the robot kit. The students who experienced the augmented reality technology did so by interacting with an animated version of the same static manual where they observed video tutorials that were overlaid onto the static manual to provide an augmented representation of each step. This technology solution was developed using the Aurasma ${ }^{\mathrm{TM}}$ augmented reality application which ran on Apple iPads $^{\mathrm{TM}}$. Results have indicated that the students who used the animated manual to learn the procedural task showcased significantly higher comprehension scores when compared to those who only used the static manual. Our findings support the claims that the integration of augmented reality into a classroom setting may be beneficial to student learning.
\end{abstract}

Keywords: Augmented Reality, Education, iPads, Aurasma, Lego robots.

\section{Introduction}

As the presence of classroom technology continually grows, the critics of academic innovations vie to be heard. Some claim that the use of technology, such as the iPad, in a classroom setting produces more distractions than learning outcomes (Mulholland, 2011). Voices such as these have inspired much study into whether or not they these devices can function as aids to learning. One emerging technological tool that has seemingly refuted negative claims about classroom technology is Augmented Reality (AR). An explanation of the technology is given by El Sayed, Zayed, and Sharawy (2010): "Augmented reality is the technology of adding virtual objects to real scenes through enabling the addi-

Material published as part of this publication, either on-line or in print, is copyrighted by the Informing Science Institute. Permission to make digital or paper copy of part or all of these works for personal or classroom use is granted without fee provided that the copies are not made or distributed for profit or commercial advantage AND that copies 1) bear this notice in full and 2) give the full citation on the first page. It is permissible to abstract these works so long as credit is given. To copy in all other cases or to republish or to post on a server or to redistribute to lists requires specific permission and payment of a fee. Contact Publisher@InformingScience.org to request redistribution permission. tion of missing information in real life".

This innovation can be very useful in an academic setting. Thornton, Ernst, and Clark (2012) make the claim that students who use AR are likely to participate more in their education since augmented reality can clearly explain complex examples by manipulating visual and spatial interactions. The Aurasma 
application for the iPad is a good example of this ability of the technology. The application boasts that it can "seamlessly animate the world as seen through a smartphone [or tablet]" (Mills \& Roukaerts, 2012). Since there have been many claims about the prospective success of AR technology systems being used in the classroom, it is important that more research is conducted.

After a review of relevant literature, this paper describes a relevant experiment undertaken by the authors at a school in upstate New York using AR technology to assist students from an elementary school while building LEGO ${ }^{\circledR}$ robots. The paper defines the research objective and the experimental method and procedures employed to assess the impact of the technology, followed by a discussion of the results and findings from this research project.

\section{Literature Review}

When testing the success of an AR system, it is important to integrate the technology into a live classroom, as opposed to a lab setting. Stanton et al. (2001) explain that augmented reality can only enhance comprehension of a task when the system is tested in the environment for which it was designed. This is because laboratories cannot account for the unexpected changes of the classroom (Cuendet, Bonnard, Do-Lenh, \& Dillenbourg 2013). Consequentially, in 2011, the Australian Learning and Teaching Council donated money to a project, entitled ARstudio, in order to perform more augmented reality research in academic settings. This project successfully integrated and tested AR systems that were tailored to specific learning scenarios (Foreshew, 2011). Further information about this project is available from the Inspire Center based at the University of Canberra. (http://www.inspire.edu.au).

The goal of the study described in this paper was to explore whether the use of the Apple iPad, in conjunction with the Aurasma augmented reality application, aided student learning when integrated into a classroom project. At the time of the study, the participating classroom was to begin a segment on simple robotics. The integration of the augmented reality technology, and the experimental evaluation of this technology, was designed to correlate with this prearranged assignment.

This study examined sixth grade students at Fitzhugh Elementary school in Oswego, New York, who were using the LEGO ${ }^{\circledR}$ brand Education WeDo construction kit. The kits were comprised of many LEGO brand parts, downloadable software, and a modest, picture only, instruction manual. Students were able to construct one of two animals with the goal being to build them into functioning robots. The LEGO manual that was provided with the kits coincides with Greenough and Fakun's (2002) description of traditional manuals. They agree that it is common for procedural information to be displayed as "drawings on paper" and that, although companies are slowly going digital, most businesses develop paper documentation. The issue with this practice is that, generally, there is no analysis of usability involved when designing these traditional procedural manuals (Greenough \& Fakun, 2002). Because many digital manuals are often tested for ease of use, they can potentially motivate and encourage engagement from users (Burbaite, Stuikys, \& Marcinkevicius, 2012).

Research has shown that "animated" manuals are often considered better than "static" representations of a procedural task because "animation can facilitate mental representation of a procedure clearly, present step by step sequential actions, and show the specific behavior or dynamic movement of the equipment, as it changes over time" (Lee \& Shin, 2012). The Aurasma application has afforded the users of their augmented reality technology the ability to enhance traditional manuals, such as the LEGO WeDo manual's static representation of each step with an animated version (Figure 1). As Lee and Shin (2012) suggest, the animated visual representations are ideal for procedural tasks because they aid the development of the student's mental model of the assignment. Additionally, the US Navy avoids the use of paper manuals when their soldiers are ex- 
pected to comprehend a procedural task because the military claims that digital manuals allow soldiers to perform a task 50\% faster and perform it $40 \%$ more accurately (Greenough \& Fakun, 2002).

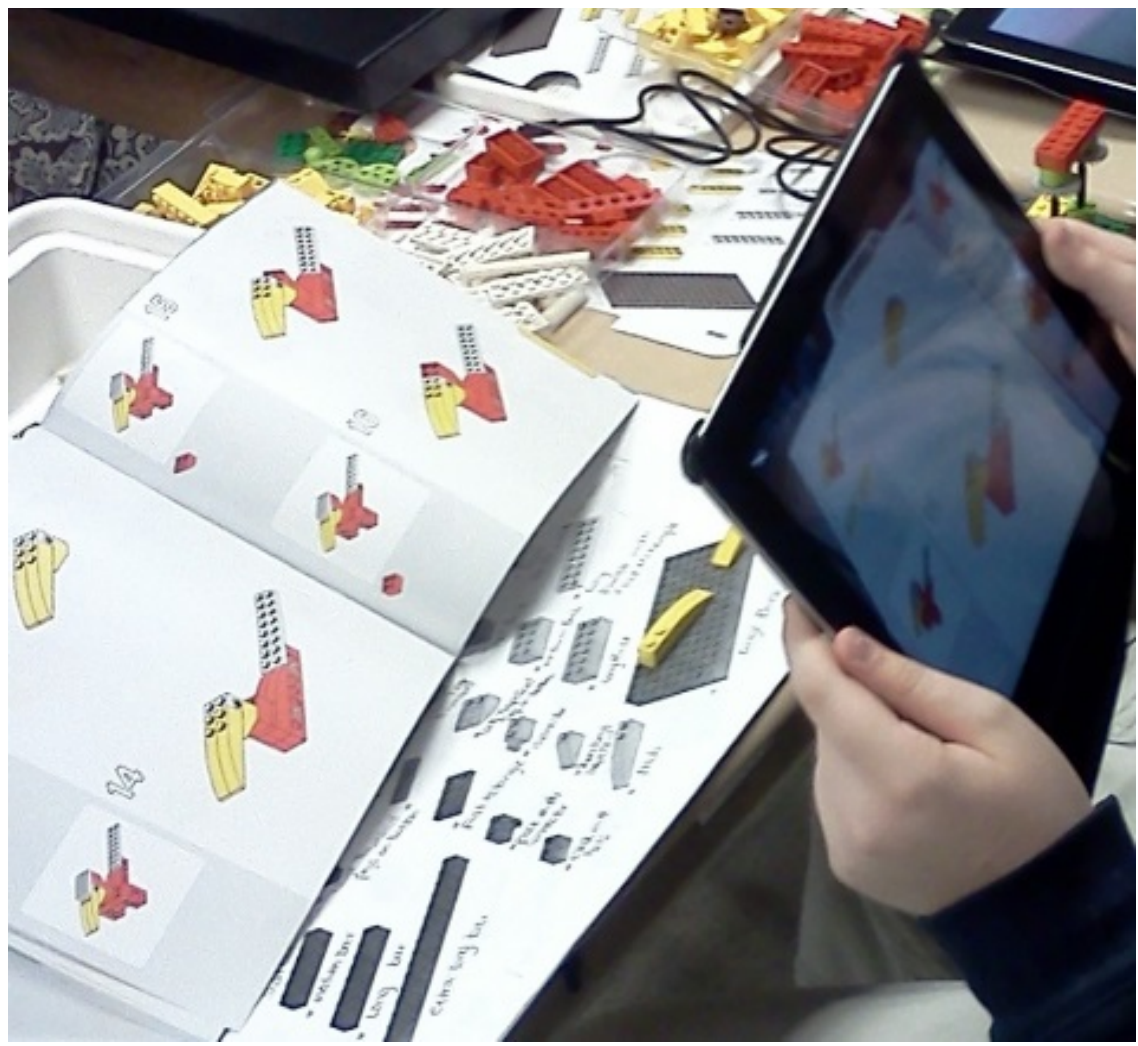

Figure 1. A view of the animated manual (developed using the Aurasma application) running on an iPad.

When technology can be effortlessly integrated into a classroom project, it is anticipated that students will show improvements in their work (Lee \& Lehto, 2013). For example, the incorporation of the Aurasma augmented reality application into a classroom by animating the LEGO WeDo kit's static manual is expected to save time, improve learning and efficacy, and help students to avoid mistakes (Greenough \& Fakun, 2002). Lee and Lehto (2013) assert that as long as the technology fits the procedural task, it will be considered a useful tool among its users. Similarly, Wu, Lee, Chang, and Liang (2013) attest to the notion that learning through augmented reality systems depends heavily on the approach. One factor of the comprehension of a given task involves understanding how well the technology enhances the task (Lee \& Shin, 2002). That being stated, Cuendet et al. (2013) suggest that this is not enough. They propose five principles that ensure learning through the use of augmented reality. Their study concludes that integration, flexibility, empowerment, minimalism, and awareness are key elements to consider when testing an AR learning system.

- Integration asks that the augmented reality system be smoothly acclimated into current classroom tasks;

- Empowerment focuses on upholding the teacher as the center of attention during the use of the system;

- Awareness ensures that the teacher can identify the status of each student at any given time; 
- Flexibility refers to the desired ability of the augmented reality system to adapt to unexpected changes;

- Minimalism asks that the system does not overload the teacher with different functions (Cuendet et al., 2013).

From the literature there is an expectation that $\mathrm{AR}$ will improve the education experience in a classroom when the guidelines for learning systems are followed. Hence, it was anticipated that the students of Fitzhugh Park elementary school would perform better when using an animated manual. Several variables were tested to detect significant differences between the traditional LEGO WeDo static manual and the version enhanced by Aurasma. These variables included several central measures of usability such as errors, efficiency, engagement, satisfaction, ease of use, learnability, and comprehension.

\section{Research Objective and Development of Hypotheses}

In order for the principles offered by Cuendet et al. (2013) to be effective, it is important to ensure that the device follows the basic heuristics of usability. It is equally essential to certify that a device recognizes these rudimentary variables as it is to seamlessly integrate the technology into a classroom setting. By calculating the errors that students made and their efficiency involved with the use of the each manual type, along with their engagement, satisfaction, and their perception about how easy the manual was to learn, we could effectively assess whether or not the Aurasma application would be beneficial as a learning tool. Since comprehension of a procedural task is the primary goal of a manual, it was added to the test variables.

With a control group that used only the static manual for two days in a row and an experimental group that used the animated manual on the first day then the static manual on the second day, comprehension was operationally defined by the time it took for the experimental group to build their robot on the second day of testing (where significantly less time equals a higher level of comprehension when compared to the control group).

H1: There is greater comprehension of a procedural task when learned through the use of a manual animated by the augmented reality iPad application Aurasma than when learned through the use of a traditional static manual.

Data on the number of errors made, efficiency, engagement, satisfaction, ease of use, and learnability were collected during the experiments.

H2: There are fewer errors made by participants who use the manual animated with the use of the augmented reality iPad application, Aurasma, than by those who use the static LEGO paper manual, regardless of whether the student built the alligator robot or the bird robot.

Efficiency and self-sufficiency are defined by several observable actions. These actions included how often the student raises a hand to ask for help from the teacher, how often the student asks for help from a peer or evaluator, when a student watches a peer assemble a robot, when a student asks to start a robot over, and when the student produces visual or audible frustration. The more often that a student yields one of these indicators then the student is considered less efficient and less self-sufficient.

H3: The students who use the manual animated with the use of the augmented reality iPad application are considered more efficient/self-sufficient at completing the procedural task when compared to the participants who use the static LEGO manual, regardless of robot type. 
Engagement is defined by the number of times a student is distracted, how often a student talks to his or her peers, how many times the student focuses on something other than building the robot, and how often the student complains about the project. The more often that a student yields one of these indicators the student is considered less engaged.

H4: The students who use the manual animated with the use of the augmented reality iPad application are more engaged during the project than the participants who use the static LEGO manual, regardless of robot type.

Satisfaction, ease of use, and learnability were measured since "user satisfaction is considered an important factor affecting the success of learning systems" (Lee \& Lehto, 2013).

H5: The students who use the manual animated with the use of the augmented reality iPad application will find the use of their manual to be more enjoyable, easier to use, and easier to learn how to use during the project than the participants who use the static manual, regardless of robot type.

\section{Method}

\section{Participants}

The subjects in this experiment consisted of one sixth grade class, composed of 19 students between the ages of 11-13. No demographic information was collected. Academic faculty involved in Project SMART (Student-centered Multicultural Active Real-world Teaching) at SUNY Oswego acted as a liaison between Fitzhugh Park Elementary and the Master's program in Human-Computer Interaction at SUNY Oswego to recruit the participants for this project.

\section{Materials}

Project SMART was interested in integrating iPad technology into a Fitzhugh Park Classroom. The selected Fitzhugh Park Classroom had a need to improve the use of the LEGO WeDo kits by the students. The iPads and LEGO kits were expected to be used collectively in this experiment. Based on these parameters, the use of the Aurasma augmented reality application was embraced by the principal investigators. The following is a description about the technology, manuals, and surveys that were provided to the students.

Technology. In the classroom, students were provided with their own LEGO brand WeDo kit that included dozens of individual LEGO brand pieces and computer attachments. Apple iPad devices from the Fitzhugh Park Elementary school's library were used for the experiment. The Aurasma application was downloaded onto each iPad and featured tutorials with which each step of the static manual was to be animated. These tutorials presented verbal representations of the instructions along with a video demonstration of the process indicated by each step. Those participants using the iPad application also received a set of headphones in order to properly hear the procedural information. A timer was also set up on the SMART board in front of the classroom. Once they completed the experiment, participants were permitted to use laptop computers in an adjacent room to test their robots with the software that accompanied the LEGO brand WeDo kits.

Manual. Each student was provided with the instructional manual that accompanied the LEGO brand WeDo kits, as well as a laminated green square that was held up to signal when the student was finished with the robot. The participants who belonged to the groups using the animated manual also received a laminated red square, which indicated an application malfunction. Since the static instructional manuals that accompanied the LEGO brand WeDo kits did not offer a vocabulary associated with each piece, all participants received a vocabulary sheet that was developed by the investigators. 
Questionnaire/Survey. The questionnaires were distributed after all participants had assembled their assigned robot on the first day. In this questionnaire, they were first asked to identify the type of animal and to which manual type they were assigned. Subsequently, using a graphic rating scale that was anchored with opposing declarations, the questions assessed the participants' opinions about their satisfaction regarding the project, the ease of use regarding the LEGO brand WeDo kits, the learnability of the kits, their satisfaction rating of the project, and the learnability of their manual type. At the end of the second day, participants were given an open ended survey that asked whether they preferred the animated or static manual, to provide descriptions of what they liked and disliked about the animated manual, and to suggest any changes that may improve the augmented reality application.

\section{Procedure}

On the first day of the study, the participants had the entire process of the experiment described to them. The investigators explained what the participants would be asked to do; the vocabulary associated with the project, and allowed them to familiarize themselves with the parts of the LEGO WeDo robot kits that they would be using.

On the following day, students were randomly placed into one of four groups. Each group was assigned to either an alligator or a bird animal type and either the static or animated manual type. One group featured the alligator/static manual and was observed by a principal investigator. Another group was comprised of participants who were assigned to bird/static manual and was observed by an assistant. A third group consisted of those with a bird/animated manual and was observed by a principal investigator, and one last group involved the alligator/animated manual and was observed by an assistant (Figure 2).

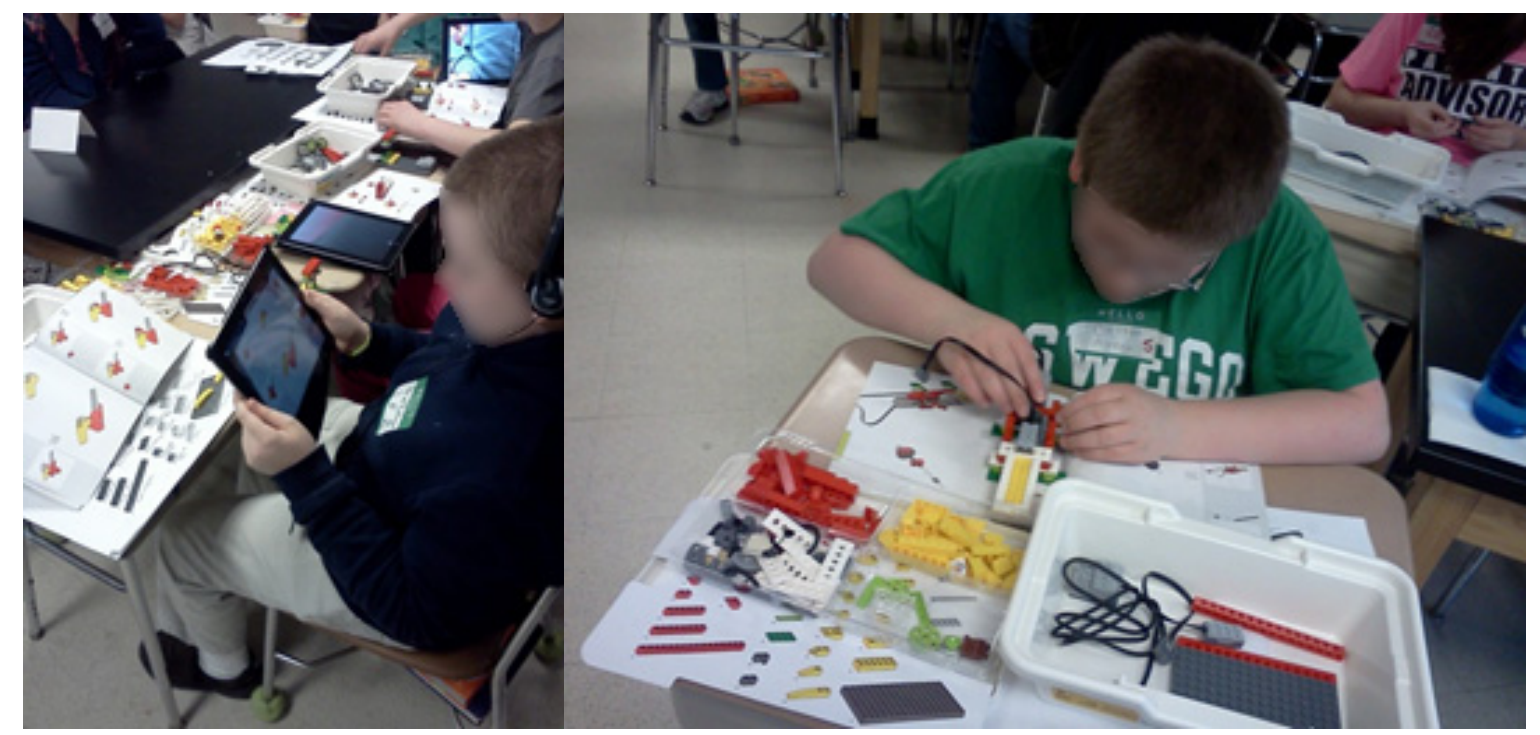

Figure 2. Student using the animated manual (left). Student using the static manual (right).

It was explained to the participants that the observers were merely proctors and that they would not answer any questions or help to remediate the issues that may arise. The students were asked to raise their laminated red square to indicate an Aurasma application malfunction and to raise their hand to prompt teacher assistance, as traditionally practiced. Additionally, the subjects were asked to raise their laminated green square to indicate that they had finished building their robot. The observers agreed to make a tally into individual boxes on a sheet that referenced each of those prospective actions, whereas the red square was intended to signify "Application malfunc- 
tion", a raised hand was intended to signify "Efficiency/Self-Sufficiency," and the green square would prompt the observer to look at the timer on the SMART board and record the time it took for that individual student to complete his or her build.

Specifically, the tally sheet measured errors made by the participant, the student's self-sufficiency while building the robot and engagement with the task at hand.

\section{Operational Definitions}

Since the Aurasma application was manipulated by the investigators to specifically enhance the static LEGO manual, it was necessary to set precise definitions for common actions while the students used their manuals. Some complications regarding these definitions were realized when the experimental procedure was introduced into the classroom environment.

- Errors were defined as "student places block incorrectly", "student skips a step", "student must reassemble", and "student must repeat a step". Malfunctions within the Aurasma software were not measured; Observed errors made by an individual student were being measured. For the two groups that observed the use of the iPad Aurasma application, a separate tally box was available to record a student's perceived application malfunction.

- "Efficiency/Self-Sufficiency" was measured by marking a tally when an observer witnessed the following; "student raises hand", "student asks for help from teacher, peer, or proctor", "student watches peer assemble their robot," "student asks to start over", "student shows visible/audible frustration".

- "Engagement" was measured by marking a tally when the observer noticed the student attending to "distractions", "student talks to peers", "student focuses on something other than project", or the "student complain about the project".

\section{Experimental Setup}

The teacher and the student teacher were both available to fill the traditional classroom teaching role when students raised their hand. Evaluators simply observed each group with as little intervention in the environment as possible. When participants raised their green square (indicating completion), their evaluator recorded their build time and they were subsequently excused from data collection to test their robot with the LEGO WeDo software on laptop computers. No data was obtained from their work with the LEGO WeDo software.

When all subjects had completed building their robot and had the chance to test it with the software, a questionnaire regarding their satisfaction, ease of use, and learnability was passed out. They had approximately ten minutes to answer each question. At the end of ten minutes, the questionnaires were collected. For the second portion of the experiment, a class of fourth grade students was invited by the sixth grade classroom teacher to observe the experiment in an effort to introduce peer-led education into the curriculum. All sixth graders were paired with a fourth grader; it is understood that every student may have been helped or distracted by the observer and may have influenced or skewed the data collected on this day.

Each sixth grade participant was assigned to their same group and was asked to build the same animal as they had on the previous day with the only difference being that no participants used the iPad and Aurasma application to animate their manual. The decision to involve more than one robot type was aimed at avoiding the fatigue effect among the students, which causes them to become disengaged due to boredom. It was only through the promise that they would soon be building the other animal robot type that they were content with building the same animal two times within two days. There were no data collected about errors, efficiency, or engagement on this day. The only variable being measured for the second day was the time it took for participants to 
complete their robot using the static manual. As established in the previous day, participants were asked to raise their green square when they were finished to indicate to the investigators that they had completed construction and their time was then recorded on a data collection sheet. When all participants had completed building their robot, the students were given another survey which featured open ended questions about the project. This was prior to the investigators completing a debriefing phase that took about twenty minutes. The survey rated participant's satisfaction, ease of use, and learnability associated with each manual.

\section{Results}

Results indicate that the average amount of time it took for participants who used the animated manual to build their robot on the first day was approximately 25 minutes on the second day $(\mathrm{M}=24.75, \mathrm{SD}=5.29)$ while the mean amount of time it took for participants who used the static manual to build their robot on the first day was approximately 32 minutes on the second day $(\mathrm{M}=32.18, \mathrm{SD}=8.49)$. A two tailed independent groups $t$ test indicated that the difference between these two groups was significant; $\mathrm{t}(17)=2.32, \mathrm{p}=.033$. According to the operational definition for comprehension, these results indicate that the participants who used the animated manual on the first day better comprehended the instructions about how to build their robot when compared to the group that used the static manual on the first day to learn how to build their robot.

A 2(animated versus static manual) X 2(alligator versus bird robot) ANOVA revealed that the number of errors made by the students using the animated manual was not significantly different from the amount of errors made by the students using the static manual $(\mathrm{F}=.840, \mathrm{p}=.374)$. Similarly, differences in the measured efficiency/self-sufficiency $(\mathrm{F}=.308, \mathrm{p}=.798)$, engagement ( $\mathrm{F}$ $=.835, \mathrm{p}=.375)$, satisfaction $(\mathrm{F}=.218, \mathrm{p}=.647)$, ease of use $(\mathrm{F}=2.384, \mathrm{p}=.143)$, and perceived learnability $(\mathrm{F}=.368, \mathrm{p}=.553)$ were not significant when comparing the manuals.

\section{Discussion and Conclusion}

As predicted, in hypothesis 1 , results indicate that there is greater comprehension of a procedural task when learned through the use of a manual animated by the augmented reality iPad application Aurasma than when learned through the use of a traditional static manual. This may be explained by the Dual-Coding theory (Lee \& Shin, 2012) which emphasizes that when a student learns something with both visual and audible stimuli, he/she has a greater opportunity of making connections and, therefore, a greater ability to recall the information that was conveyed. For example, if a student does not remember the information based on the visual stimulus, he/she has the opportunity to retrieve the information from auditory memory, and vice versa. Since the static manual only offered one type of learning stimulus (visual), the animated manual which used both visual and audible learning stimuli provided a better opportunity for the students to recall the learned information.

There were no significant differences in the number of errors made or the efficiency/selfsufficiency for each group. Eiriksdottir and Catrambone (2011) assert that more errors and less self-sufficiency are common when a procedural manual very closely resembles the task at hand because it is likely that the users are merely mimicking the actions illustrated in each step. Student imitation of the animated manual, in this experiment, may have hindered them from creating the mental models required to perform a procedural task without teacher assistance.

In this study, results indicated no difference between the levels of engagement found in each group. This may be explained by the claim that "using robot based tools for learning," such as the LEGO brand WeDo robots, can "increase the engagement level in learning for all students despite their abilities" (Burbaite et al., 2012). Therefore, the mere act of playing with the LEGO brand 
WeDo robotic kits may have influenced the equally high levels of engagement among all of the students regardless of manual and robot type.

Additionally, the friendships that existed between students were likely to cause disruption and disengagement because all four groups of students built their robots in the one classroom. Due to this arrangement, the students who constructed their robots at a slower pace were able to witness some of their peers finishing before them, which undoubtedly increased frustration. One limitation that was a concern since the design of the experiment involved the selection of two different animal robot types.

When participants from this experiment were surveyed, 90\% claimed that, if given the opportunity to build another LEGO brand WeDo robot, they would prefer to use the static paper manual over the version of the manual that was animated using the iPad and Aurasma application. This reaction speaks to the participant's level of enjoyment with the animated manual because usability often affects the level of enjoyment regarding technology. Even though the statistical analysis found no significant differences in satisfaction between the groups, the majority of students reported that the iPad application was difficult to use and to understand. The perceived ease of use of each manual was not significantly different between the groups but it is possible that complaints about the ease of use concerning the animated manual were because the Aurasma application was not developed specifically to animate a static manual the same way it was utilized in this study.

The most common responses regarding the features that participants disliked when using the animated manual was that the application would sometimes malfunction by showing the wrong tutorial for the step that they wished to animate. It is likely that encountering this error decreased the learnability for the animated manual. Although, statistically, there was not a difference between the animated and static manual in terms of errors made, efficiency, engagement, satisfaction, ease of use, and learnability, results indicated that those participants who had used the animated manual experienced a significantly higher level of comprehension. With the input of the participants of this study, it is expected that the Aurasma augmented reality application could be an essential tool aiding in student's comprehension of a procedural task.

Augmented reality in education is a viable option for educators to improve subject comprehension. The students of this experiment retained the information that was relayed to them through the manual that was animated with augmented reality well enough to conclude that the technology can be utilized in the classroom to their benefit.

To a great extent, further research should be conducted in the emerging process of augmented reality for education, considering that there were several usability issues with the Aurasma application. For example, the students had to hold the iPad over their static manual through the entirety of the animation before setting it down to perform the task that was showcased in that step. Additionally, in most cases, the students had to stand to capture the entire page within the iPad camera's view which caused greater discomfort when compared to the students who used the static manual. To rectify this issue, further research into use of smaller devices, such as the Apple iPod Touch or Apple iPhone, is recommended.

\section{Acknowledgements}

We would like to extend our gratitude to Anthony Kirkpatrick and Bryan Kern for assistance with data collection. We sincerely appreciate Carol Carroll for inviting us into her classroom and Fitzhugh Park Elementary for being so open and welcoming throughout the investigation. Special thanks are also due to Barbara Beyerbach and all members of Project SMART for their help and feedback. 


\section{References}

Burbaite, R., Stuikys, V., \& Marcinkevicius, R. (2012). The LEGO NXT robot-based e-learning environment to teach computer science topics. Electronika IrElektrotechnika, 18(9), 113-116.

Cuendet, S., Bonnard, Q., Do-Lenh, S., \& Dillenbourg, P. (2013). Designing augmented reality for the classroom. Computers \& Education, 68, 557-569.

El Sayed, N. A. M., Zayed, H. H., \& Sharawy, M. I. (2011). ARSC: Augmented reality student card. Computers \& Education, 56(4), 1045-1061.

Eriksdottir, E., \& Catrambone, R. (2011). Procedural instructions, principles, and examples: How to structure instructions for procedural tasks to enhance performance, learning, and transfer. Human Factors, 53(6), 749-770.

Forshew, J. (2011, September 27). Local classrooms to get dose of augmented reality. Retrieved from http://www.theaustralian.com.au/technology/classrooms-to-get-dose-of-augmented-reality/storye6frgakx1226147361664

Greenough, R. M., \& Fakun, D. (2002). Evaluation of the usability of digital maintenance manuals developed without either user input or a task analysis. International Journal of Systems Science, 33(6), 451460.

Mills, M., \& Roukaerts, T. (2012). Matt Mills: Image recognition that triggers augmented reality [Motion picture]. TED Talk. Found on March 14, 2013 at: http://www.ted.com/talks/matt_mills_image_recognition_that triggers_augmented_reality.html

Mulholland, J. B. (2011). iPads strengthen education. Government Technology, 24(4), 20-24.

Lee, D., \& Lehto, M. R. (2013). User acceptance of YouTube for procedural learning: An extension of the Technology Acceptance Model. Computers \& Education, 61, 193-208.

Lee, D., \& Shin, D. (2012). An empirical evaluation of multi-media based learning of a procedural task. Computers in Human Behavior, 28, 1072-1081.

Stanton, D., Bayon, V., Neale, H., Ghali, A., Benford, S., Cobb, S., Ingram, R., O’Malley, C., Wilson, J., \& Pridmore, T. (2001). Classroom collaboration in the design of tangible interfaces for storytelling. CHI '01 Procedings of the SIGCHI Conference on Human Factors in Computing Systems, ACM New York, 482-489.

Thornton, T., Ernst, J. V., \& Clark, A. C. (2012). Augmented reality as a visual and spatial learning tool in technology education. Technology \& Engineering Teacher, 71(8), 18-21.

Wu, H., Lee, S., Chang, H., \& Liang, J. (2013). Current status, opportunities and challenges of augmented reality in education. Computers \& Education, 62, 41-49.

\section{Biographies}

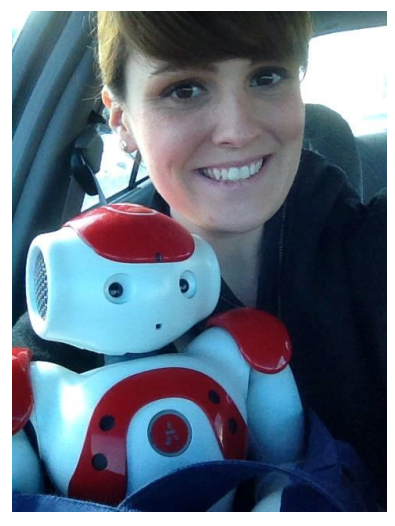

Patricia Tanner. After completing a Global Laboratories internship at a federal university in Joao Pessoa, Pariaba, Brazil this summer, Patricia will be graduating with a M.A. in Human-Computer Interaction. With a strong desire to use technology as a vehicle for multi- cultural and interdisciplinary education, Patricia has been associated with several successful committees and programs, such as, Project SMART (Student-centered, Multicultural, Active, Real-world Teaching), The Research Foundation for SUNY: NCSTEP (North Country Science and Technology Entry Program), and IPAC (Interdisciplinary Programs and Activities Center). Most recently, Patricia has accepted a position as a Usability Specialist at the Xerox Research Center of Webster, New York. 


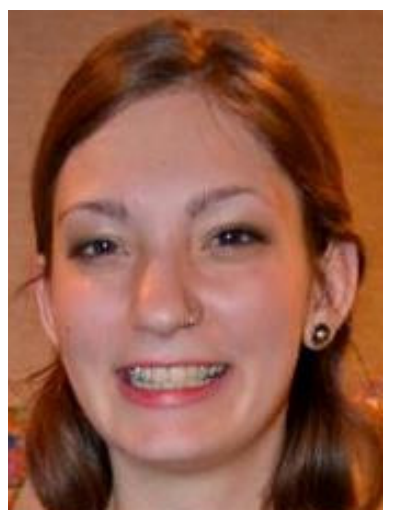

Carly Karas has a background in graphic design and cognitive science and she is currently studying towards her M.A. in Human-Computer Interaction at the State University of New York. While undertaking her masters research Carly has been associated with Project SMART (Student-centered, Multicultural, Active, Real-world Teaching) and the Research Foundation for SUNY: NCSTEP (North Country Science and Technology Entry Program).

Last year, Carly travelled to Australia and worked on projects with RMIT University in Melbourne, involving robots and Transhumanism. She was subsequently involved in the development of a number of short films using the robots as cyborg thespians.

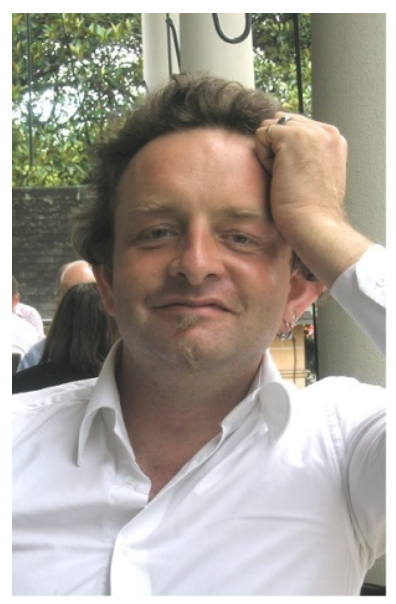

Dr. Damian Schofield is currently Director of Human Computer Interaction (Full Professor) at the State University of New York (SUNY). $\mathrm{He}$ is also an Adjunct Associate Professor at Edith Cowan University in Perth, Australia. Dr. Schofield also remains a director and major shareholder of Aims Solutions Ltd., a UK based company created in 2000 , to provide computer graphics visualisation services and virtual reality based simulation training products to a wide range of public and private sector organisations.

Dr. Schofield has been involved in research examining the use of digital technology in both courtrooms and classrooms, particularly virtual reconstructions, for many years. He is specifically interested in the representation and understanding of visual information in these environments. 